\title{
MODELLING OF THERMAL TRANSIENT PHENOMENA IN AXIAL FLUX PERMANENT MAGNET MACHINE BASED ON COUPLING OF TWO SEPARETED MODELS - ELECTRICAL AND THERMAL MODELS
}

The paper deals with transient thermal modelling of air cooled axial flux permanent magnet machine. It has a rotor with permanent magnets placed on the rotor surface situated between two stators. The simulation model consists of two equivalent circuits - electrical equivalent circuit and thermal equivalent circuit to cover various machine operations. This model can be very useful mainly in mechatronic applications in order to be sure that applied machine will manage with requirements put by operation conditions and environment roughness.

\section{Introduction}

With the coming of automobile industry to the Slovak Republic, an interest in mechatronic has increased and mechatronic applications have been under the greater investigation of many researchers, too.

Synchronous machines with permanent magnets have been more and more popular in the field of electrical drives in the last decades. They have many advantages in comparison with classical synchronous machines with d. c. excitation. Of course, they have some disadvantages, especially impossibility of controlling by varying types of excitation. In the past, prime interest was given to radial flux permanent magnet machines (RFPM). Recently, greater development of axial flux permanent magnet machines has been introduced to industry. In general, it is known that AFPM feature analogous operation behavior as RFPM but their geometrical dimensions and small moment of inertia are major profits. This could be very useful in mechatronic applications.

Mechatronic applications are characterized by short time multiple overloading of an applied machine. This overloading can lead to degradation and faster ageing of construction materials, thus decreasing machine lifetime. Therefore, it is very important to know the thermal behavior of machine in order to prevent early failure of the machine.

During operation of the machine, different types of losses are generated, namely losses in the stator yoke, losses in the stator teeth, losses in permanent magnets (PM), mechanical losses (they can be neglected in the case of a low speed machine) and Joule losses, which present dominant heat source. In the case of AFPM, the winding losses are organized to outer and inner endwinding losses and losses in the slot part of winding.
The paper focuses on finding a suitable simulation model in order to find limits for overloading permitted to prevent the machine failure due to overheating.

\section{Simulation model}

The simulation model was developed for air naturally cooled AFPM with construction stator-rotor-stator, see Fig. 1, with the following nameplate: $P_{N}=5000 \mathrm{~W} ; T_{N}=159 \mathrm{Nm} ; V_{N}=230 \mathrm{~V}$, winding connected to star; $f=30 \mathrm{~Hz} ; I_{N}=8.4 \mathrm{~A} ; 2 p=12$; $n=300 \mathrm{rpm}, \mathrm{Br}=1.05 \mathrm{~T}$. This model is mainly oriented to investigate how Joule losses affect the heating of the machine during operation.

Previously, the steady state thermal model of the investigated motor was developed in [1]. The thermal model of AFPM was extended with thermal capacitances to cover the transient thermal analysis. The thermal model was also made by electrical equivalent circuit up to gain a possibility of the different operation duties investigation.

The overall simulation model involves an electrical equivalent circuit based on equations of general theory of $\mathrm{AC}$ machines transformed to $d, q, 0$ reference frame. Equations for AFPM do not differ from equations validated for RFPM which may be found in many publications, for example [2], [3], [4] and others.

The system of equations, used to describe the electrical equivalent circuit, can be summarized as follows:

$$
u_{d}=R_{s} i_{d}+L_{d} \frac{d i_{d}}{d t}-\omega L_{q} i_{q}
$$

\footnotetext{
${ }^{*}$ Eva Belicová

Nuclear Power Plant Research Institute (VUJE), Okruzna 5, 91864 Trnava, Slovakia, E-mail: eva.belicova@gmail.com
} 


$$
\begin{aligned}
& u_{q}=R_{s} i_{q}+L_{q} \frac{d i_{q}}{d t}+\omega L_{d} i_{d}+\omega \psi_{P M} \\
& m_{e}=p\left[\left(L_{d} i_{d}+\psi_{P M}\right) i q-\left(L_{q} i_{q}\right) i_{d}\right] \\
& J \frac{d \omega}{d t}=p\left(m_{e}-m_{L}\right) \\
& \vartheta_{r}=\int \omega_{r} d t
\end{aligned}
$$

Where $u_{d(q)}, i_{d(q)}, L_{d(q)}, R_{s}, \omega, m_{e}, p, J, m_{L}, \vartheta_{r}, \omega_{r}$ are voltages, currents and synchronous inductance in $d(q)$ axis, phase resistance, electromagnetic torque, number of pole pairs, moment of inertia, load torque, rotor position angle and mechanical rotor speed, respectively. Voltages in $d(q)$ axis are given by Park's transformation of phase voltage waveforms. To keep an invariance principle of powers, transformation constants were chosen as $k_{d(q)}=$ $=\sqrt{2 / 3}$.

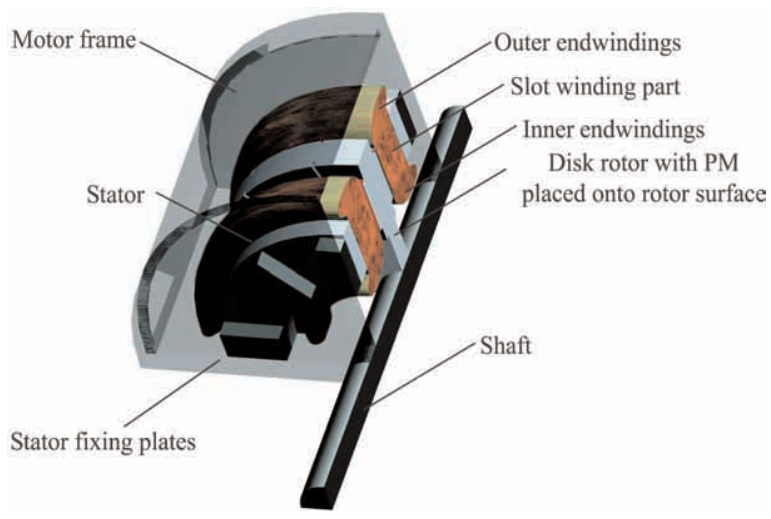

Fig. 1 Slit of analyzed AFPM

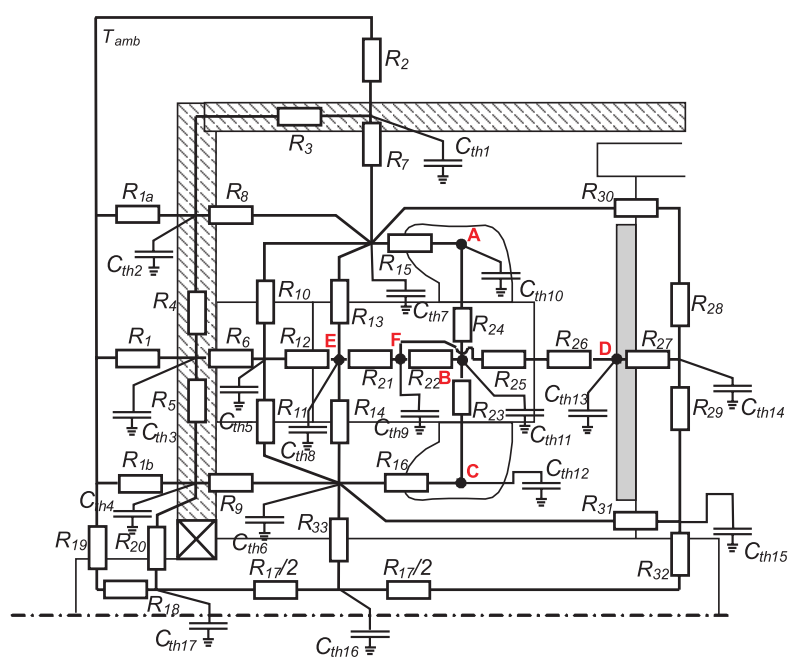

Fig. 2 Simplified thermal network of analyzed AFPM

A - Outer endwinding; B - Slot part of winding; C - Inner endwinding D - Permanent magnets; E - Stator yoke; F - Stator teeth
The phase current waveform is gained by using the backward Park's transformation from the system mentioned above. Consequently the root-mean-square value of the stator current IRMS was evaluated to determine the Joule losses in the stator winding which denote the dominant heat source. These losses are dependent on the temperature rise because the value of stator resistance alters with the temperature and affects size of Joule losses, too.

The thermal network of AFPM is shown in Fig. 2. This thermal network model consists of thermal resistances that are determined based on the type of heat transfer and thermal properties of used construction material; see [5]. All the analyzed nodes have assigned the thermal capacitances, which present stored energy. The letters A-F show where individual losses input into the thermal model as the heat sources, see Fig. 2.

The transient thermal simulation was realized by using the following differential equation:

$$
\frac{d}{d t}(\Delta \vartheta)=C^{-1}\left(\Delta P_{d}-G(\Delta \vartheta)\right)
$$

Where $\Delta \vartheta, \Delta P_{d}, C^{-1}, G(\Delta \vartheta)$ are a temperature rise vector, vector of the dissipated losses, an inverse matrix to a capacitance matrix and a thermal conductance matrix, respectively. Elements of the capacitance matrix are equal to zero except main diagonal where particular thermal capacitances are located. The elements of the main diagonal of the conductance matrix were assigned with a sum of the thermal conductances that are connected to the particular nodes. The other components are defined by the thermal conductance located between the corresponding nodes.

The principal block diagram of the overall simulation model is shown in Fig.3. It is very clearly seen from the figure how temperature affects individual components of the simulation model. Some of the thermal resistances, mainly the thermal resistances of parts filled by air, are dependent on the temperature and they must be regularly updated. In the figure, there is also shown feedback loop from the thermal equivalent circuit to the electrical equivalent circuit to update the value of the stator resistance, and so it is provided, the correct value of the stator resistance is taken into account. Based on this mutual affecting, the changes of the model parameters that appeared in the machine during operation are more precisely included during simulation. In this way, it is possible to involve changes of the thermal equivalent circuit as well as of the electrical equivalent circuit with quite a good accuracy.

\section{Simulation results}

The simulation model was built in Simulink. One operation duty cycle was selected to verify the model's accuracy. Both simulation models were running at the same time. The machine was started up and loaded with the nominal torque after the $1.5 \mathrm{~s}$, see Fig. 4a). The root-mean-square current was gained from electrical model. The Joule losses were calculated for the current temperature in every simulation step by the current value (see Fig. 4b)) as well as by the value of stator resistance, see Fig. 4c). 


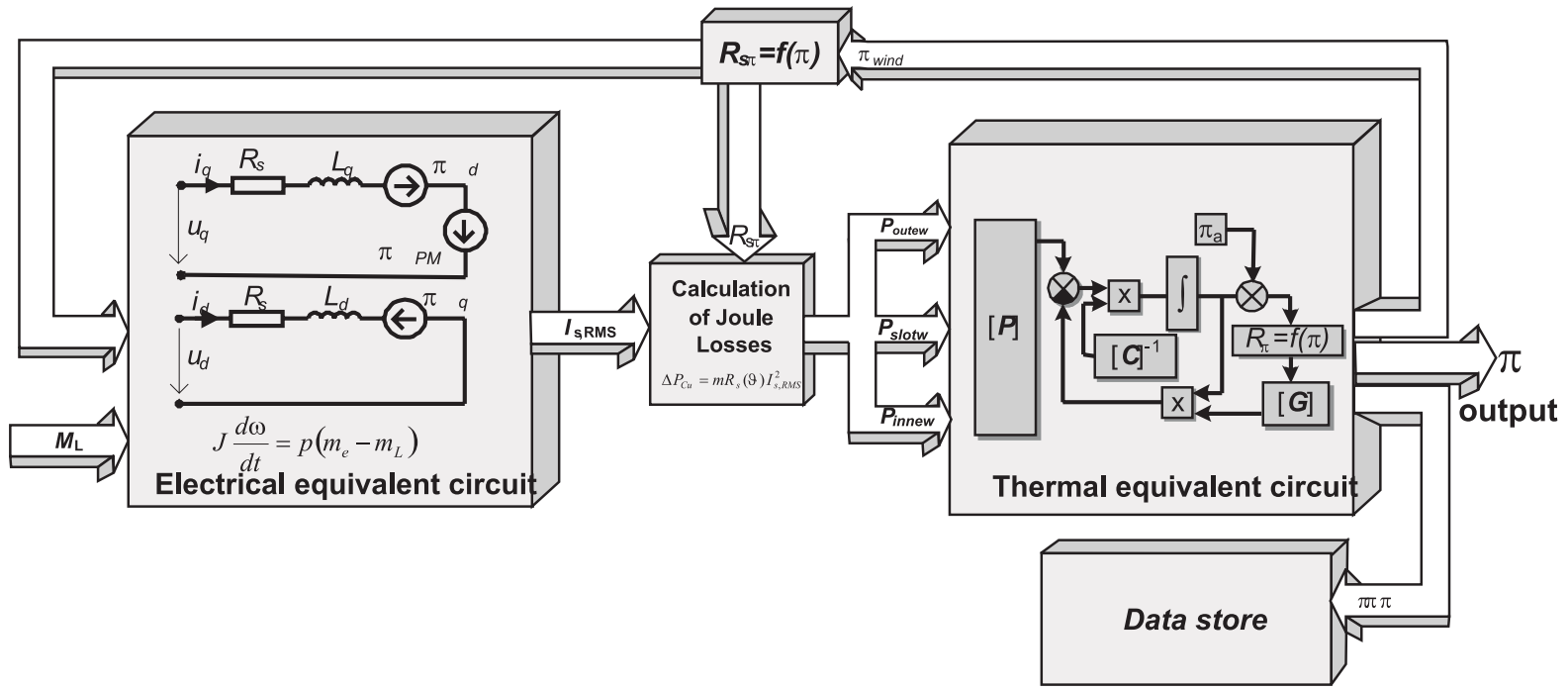

Fig. 3 Block diagram of the simulation model

The total Joule losses were divided into three parts; outer and inner endwinding Joule losses as well as slot part of winding losses, in a ratio which corresponds to the resistance values of the individual winding parts, see Fig. 4d). Other losses generated inside the machine were kept constant during the whole simulation because their variation was not so notable. Here must be noted that all the values of thermal capacitances were also kept constant in every node.

The simulation had been running till the stable values of the temperature were reached. As it is seen in Fig. 4b) the root-meansquare value of the current was risen by temperature increase which
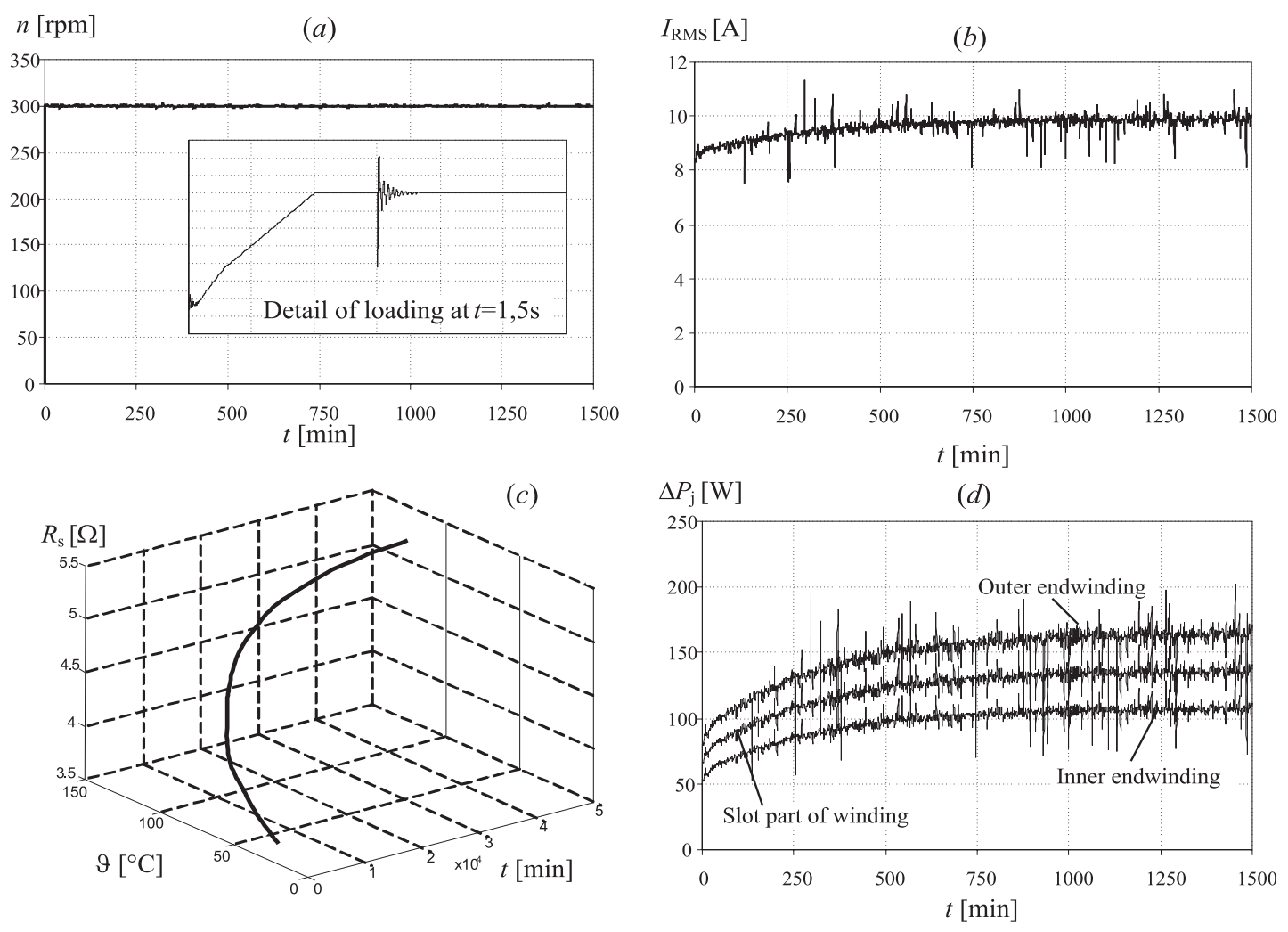

Fig. 4 Simulated waveforms of (a) revolutions with a detail of loading; (b) root-mean-square phase current (c) stator resistance versus temperature at given time (d) Joule losses in outer and inner endwinding and in slot part of winding 

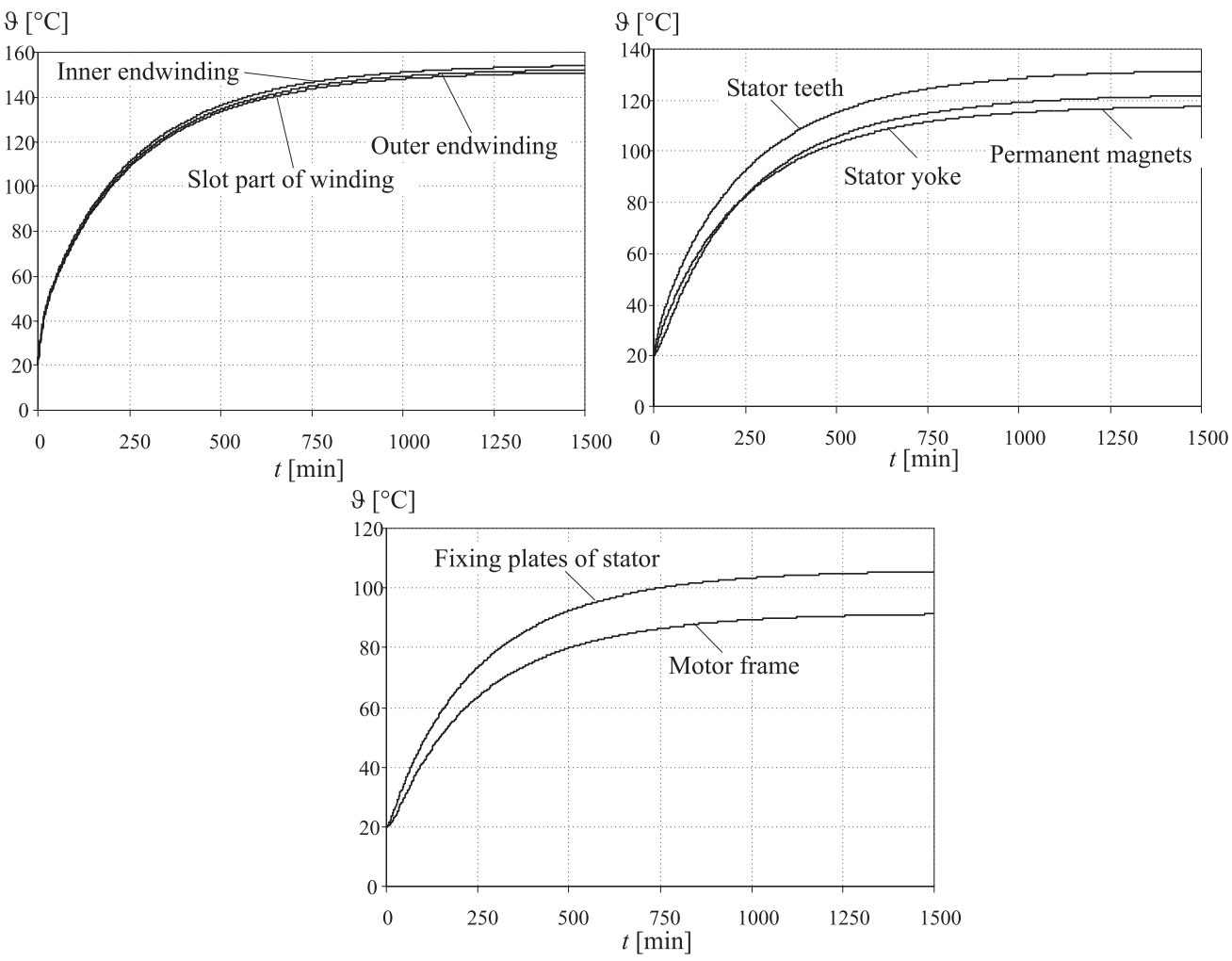

Fig. 5 Temperature curves of individual analyzed nodes of AFPM

was caused by the Joule losses rise. While it was requested to have a constant output power on the shaft, and the machine was supplied from a constant voltage source, the input power had to be increased by varying the input current value. The existence of peaks in the current and the Joule losses waveforms could be caused by sensitivity of the electrical simulation model to the resistance changes.

The simulation time was set up to 25 hours of continuous machine operation under the full load. The simulation of the given operation period consumed 23 hours of the real time on the computer with $2.8 \mathrm{GHz}$ processor and $2 \mathrm{~GB}$ RAM.

In Fig.5 temperature curves of analyzed nodes are shown. As it is seen from the figure, the machine was operating under conditions which did not affect its lifetime. The insulation used in the machine belongs to the thermal-insulation of $\mathrm{B}$ class, which has the upper limit temperature about $170{ }^{\circ} \mathrm{C}$ if air-cooling of the machine is considered. The operation temperature of PMs used in the investigated machine is $150{ }^{\circ} \mathrm{C}$. This value does not present risk of their properties degradation if an ambient temperature was considered about $20^{\circ} \mathrm{C}$.

The prime advantage of such a simulation model is a possibility to investigate different operation modes. Mainly, when the simulation model is used to investigate period overloading or starting up, which are typical operations of mechatronic applications.
The thermal network model could be replaced by a finite element model of analyzed machine, which can bring a more precise solution. In this way it will be possible to create a direct online solution. This interconnection of the electrical equivalent circuit and finite element model will be done in the future.

\section{Conclusion}

The paper deals with the transient thermal analysis of AFPM based on coupling two equivalent circuits, electrical and thermal. This approach will be suitable if operation conditions are not defined exactly.

The simulation model was built in Simulink on the base of differential equations to obtain the stator current waveform. The RMS value of the stator current was determined from the stator current waveform and this value was used to find out Joule's losses in the stator winding which were used as heat sources for a thermal network model of AFPM. The stator resistance variation caused by winding temperature changes was taken into account.

In this manner it is possible to find suitable use of machine in the mechatronic field. Moreover, it will be useful to get optimal operation of the machine to prevent reducing the machine lifetime. 


\section{Acknowledgement}

This work was supported by Science and research Assistance Agency under the contract No. APVT-20-039602 and by the Scien- tific Grant Agency of the Ministry of Education of SR and the Slovak Academy of Science under contract No. VEGA 1/2052/05 and No. VEGA 1/3086/06.

\section{References}

[1] PARVIAINEN, A.: Design of Axial-Flux Permanent-Magnet Low-Speed Machine and Performance Comparison between Radial-Flux and Axial-Flux Machines, Dissertation Thesis, Lappeenranta University of Technology, 2005

[2] HRABOVCOVÁ, V., JANOUŠEK, L., RAFAJDUS, P., LIČKO, M.: Modern electrical machines (in Slovak), EDIS, Zilina, 2001

[3] HRABOVCOVÁ, V., BRŠLICA, V.: Disk Synchronous Machine with Permanent Magnets - Electric and Thermal Equivalent Circuits, Proc. of Electrical Drives Symposium, Capri, Italy 1990, p. 163-169

[4] HRABOVCOVÁ, V., RAFAJDUS, P., FRANKO, M., HUDÁK, P.: Measurement and modelling of electrical machines (in Slovak), EDIS, Zilina, 2004

[5] INCROPERA, F. P., DE WITT, D. P.: Fundamentals of Heat and Mass Transfer, USA, 2002. 